Carmen Soares

Maria do Céu Fialho

María Consuelo Alvarez Morán

Rosa María Iglesias Montiel

Coordenação

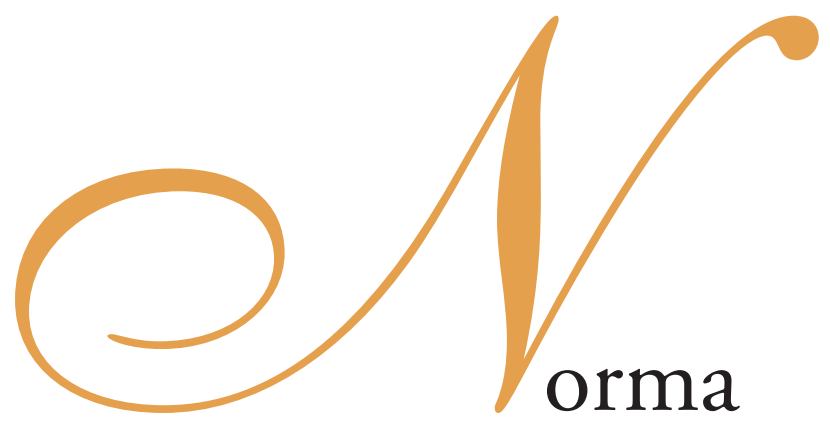

\& Transgressão

II

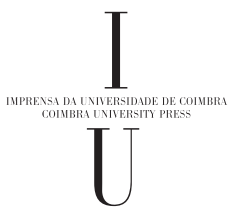


(Página deixada propositadamente em branco) 


\section{ADAPTAÇÃO DRAMÁTICA E TRANSGRESSÃO ${ }^{1}$}

As representações do drama grego antigo em diversos palcos do mundo contemporâneo, em particular na Europa, evidenciaram um incremento considerável a partir da segunda metade do século passado². Factores como a tendência para estabelecer uma ligação estreita com a situação sóciopolítica do momento/ local da performance, a actualidade de determinados temas num universo marcado por uma constante destabilização do 'ego', individual e/ ou colectivamente considerado, o relevo crescente concedido ao director, no início do século vinte, ou também o desenvolvimento dos meios audiovisuais terão contribuído, decerto, para uma tal proliferação.

Com frequência, as produções vêem-se aliviadas do universo mítico e histórico do teatro clássico, constituindo-se cada vez mais como uma possibilidade metafórica de exprimir questões, experiências, situações da vida moderna. O texto torna-se sobremodo um pretexto para adaptações várias, muitas vezes mescladas de elementos alheios à tradição teatral do

\footnotetext{
${ }^{1}$ A presente reflexão decorre do Curso de Verão promovido pelo European Network of Research and Documentation of Ancient Greek Drama entre 6 e 20 de Julho de 2008, em Epidauro.

${ }^{2}$ Cf. E. Fischer-Lichte 2008: 27 sqq.

A propósito dos três períodos considerados na História moderna da encenação, cf. E. Stehlíková 2008: 175 sqq.

The European Network of Research and Documentation of Performances of Ancient Greek Drama, com uma equipa internacional de investigadores, tem vindo a reunir informações sobre modernas performances europeias de peças clássicas, no intuito de criar uma base de dados expressiva da partilha de uma herança cultural comum, tradutora da ideia de 'unidade na diversidade'.
} 
ocidente (e. g. indianos, chineses, japoneses), reflexo de sociedades multiculturais, reflexo da época da globalização. Peças clássicas vêem-se assim alteradas, em consequência de contextos específicos e de necessidades variadas sentidas por diversos directores hodiernos, que procuram soluções inovadoras, susceptíveis de garantir, hoje, o potencial comunicativo do teatro (cf., e. g., A. Vitez (1986), Sophocles. Electra; Peter Stein (1994), Oresteia; S. Braunschweig (2002) Prometheus Bound).

O drama grego permanece como modelo, mas revela-se, em simultâneo, um material disponível para constantes reformulações, manifestas ora em pequenas mudanças patentes nas performances, ora em variações mais profundas. A encenação de uma mesma peça em locais e/ ou momentos históricos distintos, por directores diferentes, origina por isso representações diversas, produtos e produtoras de leituras múltiplas. Preservar a essência da produção antiga, nomeadamente em termos de estrutura, de situações, de caracteres, ou, em vez disso, fazer dela apenas um ponto de partida para criações mais ousadas e, muitas vezes, controversas, são opções geradoras de efeitos díspares. Na verdade, em representações que elegem como um dos seus elementos primordiais a comunicação efectiva com o público coevo, a modificação do original grego desencadeia reacções diferentes, quer entre os críticos, quer entre uma audiência conhecedora da peça clássica, embora com contextos de referência naturalmente diversos dos que tinham os espectadores da Antiguidade ${ }^{3}$. A percepção das inovações, ora favorece, de facto, um elo forte de adesão/ identificação com as escolhas, não raro surpreendentes, ditadas pelas vivências modernas, ora estabelece uma relação de fractura face às alterações operadas numa produção antiga tradicional, cujo âmago se torna, por vezes, difícil de discernir.

A adaptação dramática abre assim um leque de interpretações e de respostas variadas, passíveis de uma permanente reformulação no que diz respeito a

\footnotetext{
3 Comédias aristofânicas como Vespas ou Cavaleiros, onde a sátira política a Cléon, por exemplo, era evidente para os Atenienses da época, não teriam hoje o mesmo impacto em termos de paródia política, uma vez que o campo referencial dos espectadores contemporâneos não contempla uma série de dados históricos significativos para o público de outrora.
} 
identidades culturais, políticas, sociais, religiosas. O potencial transformativo do teatro propicia a formação de identidades renovadas, circunstância adequada ao mundo que hoje habitamos, de contínua mudança, a um ritmo vertiginoso, motivo de instabilidade reiterada para o 'ego'. A relação imediata de comunicação entre actores e público parece ganhar algum terreno face à dimensão estética, ao horizonte histórico das peças ou à análise dos textos respectivos.

$\mathrm{Na}$ Grécia moderna em geral, as representações do drama antigo atraem um número considerável de espectadores ao teatro, em especial durante os numerosos festivais de Verão que todos os anos se multiplicam pelo país, em espaços arqueológicos ao ar livre . Movido decerto por razões históricas e de identidade nacional, o público mostra-se muitas vezes particularmente sensível às modificações relacionadas com o drama clássico, encarado como algo respeitável e, para alguns, intocável até. Em consequência, uma adaptação dramática que provoca incómodo ou escândalo numa terra que é 'herdeira directa' do teatro da Antiguidade, constrangendo os Gregos a reconsiderar os conceitos sobre o seu próprio passado e sobre o carácter monumental e quase sagrado por norma atribuído às produções clássicas, pode não o causar num outro país.

Karolos Koun (1908-1987), um director helénico de renome, que influenciou de modo muito significativo o teatro grego moderno ${ }^{5}$, viu suspensa em Atenas, em 1959, a produção que dirigiu de As Aves, após a primeira performance no Herodium, conhecido anfiteatro romano vizinho da Acrópole, como é sabido. Na verdade, apesar de se tratar de uma comédia, por natureza mais versátil a alterações, a apresentação colidiu com as expectativas de parte da audiência, não predisposta para aceitar e/ ou apreciar um espectáculo inovador daquela peça clássica ${ }^{6}$.

\footnotetext{
4 Festivais anuais como os de Atenas e Epidauro convertem-se em importantes eventos culturais na Grécia actual, ponto de encontro de figuras ligadas ao teatro e também à política.

5 E. g.,contestando a monumentalidade e o formalismo de certas produções do drama antigo, para as quais advogava soluções mais simples; procurando inspiração na cultura popular grega.

${ }^{6}$ Cf. a existência de duas posições, na Grécia do século XX, face à adaptação dramática de peças da Antiguidade Clássica: os 'conservadores' defendem a imitação dos antepassados;
} 
O local aberto no qual a representação teve lugar convidava a um estilo diferenciado, no que toca a questões de actuação (e. g. gestos) e de encenação (e. g. dança, cenários) $)^{7}$. No dizer de Koun, "o teatro aberto, característico da nossa prática teatral nos últimos anos (...), solicita (...) a criação de atmosfera. Não o mesmo tipo de atmosfera conhecida dos teatros cobertos, mas a sua própria; grandes dimensões e a atmosfera alegre de uma feira" Nesta perspectiva, a encenação de As Aves era alegre em geral, colorida, com uma natureza festiva, aberta a qualquer tipo de audiência: não era absolutamente necessário conhecer Aristófanes para entender a performance. De resto, elementos como a presença de um sacerdote ortodoxo evidenciavam uma meditada combinação entre presente e passado, capazes de conduzir a uma actualização da mensagem. A coreografia, por sua vez, baseava-se em movimentos de diferentes espécies de pássaros, admitindo pequenos grupos de dois ou três actores no papel de corujas, por exemplo, com uma animação característica, que permitia destacar uma certa individualidade no coro, não convencional ${ }^{9}$. A música, por seu turno, composta por M. Katzidakis, foi pensada de acordo com o drama e com o seu conteúdo, pelo que parecia reproduzir, com extraordinária mestria e impacto, sons reais de aves ${ }^{10}$.

Esta inovadora forma de aproximação do grandioso drama antigo, que implicava criatividade do encenador moderno, conexão com a realidade da plateia sua contemporânea, apelo ao designado 'expressionismo popular', inserindo-se no carácter pedagógico e social que Koun preconizava para o teatro clássico, provocou incómodo no Herodium, em 1959.

Três anos após a polémica estreia em Atenas, o espectáculo foi porém acolhido com grande aplauso num festival internacional de Paris, onde

os 'inovadores', por seu turno, a reinterpretação das obras antigas. A este propósito, cf. V. López Recio 2009: 367 sq.

7 Sobre o recurso a locais arqueológicos para cenário de performances do teatro antigo na Grécia contemporânea, cf. P. Mavromoustakos 2008: 183 sqq.

8 K. Koun 1987: 29 .

9 Cf. vídeo exemplificador do movimento do coro em http://www.youtube.com/ watch?v=Q8BI0_BiYtM.

10 Cf. http://www.youtube.com/watch?v=MywJSmyzPLw. 
obteve o primeiro prémio. As Aves, sob a direcção de Karolus Koun, converteram-se numa produção histórica de enorme sucesso, sintomaticamente reposta no moderno National Grand Theatre da China, no ano em que se comemorou o primeiro centenário do nascimento de Koun (2008): o tema da busca de um lugar utópico não é seguramente estranho nem desadequado àquela plateia oriental, como tão pouco a plateias do mundo inteiro ${ }^{11}$.

Mais recente, e recebida como uma forte provocação à tradição do teatro clássico, revelou-se a adaptação moderna das Bacantes de Eurípides por Mattias Langhoff, em 1997. As convicções deste director explicam em boa medida as opções que fez e o violento impacto causado na crítica e na audiência gregas pela produção que dirigiu ${ }^{12}$.

Em desacordo com a característica ligação do teatro com o sagrado, M. Langhoff mostra uma forte crença na estreita conexão entre o drama antigo e a vida contemporânea. Nessa perspectiva, defende que uma performance deve produzir agitação no público hodierno, que identifica no palco questões e vivências do seu quotidiano, sendo que a resposta dos espectadores possibilita o aperfeiçoamento do teatro.

Na produção de 1997, o cenário, o trajo, o coro contam-se entre os ingredientes motivadores da reacção controversa da audiência grega, porquanto desrespeitadores dos padrões estabelecidos pela antiga tradição - os antecedentes culturais dos Helenos favoreceram a rejeição de uma performance muito distante da tragédia clássica, antes de mais em termos éticos e estéticos. Na verdade, animais mortos suspensos, o túmulo de Sémele, sobre o qual se vê um rádio que transmite notícias, roupa lavada pendurada numa corda, um telefone fixo, usado por Agave para chamar Penteu e Cadmo, a fim de que eles vejam o leão que matou, são alguns dos elementos constituintes do cenário, resultado de uma reinterpretação pessoal do drama. O coro, por seu turno, vestido com diferentes trajos de donas de casa ou

11 Cf. http://newsreleases.upstreamasia.com/news/2008/01/18/\%E2\%80\%98the-birds\%E2\%80\%99aristophanes-greek-art-theatre-\%E2\%80\%93-theatro-technis-\%E2\%80\%98karolos-koun\%E2\%80\%99.

12 A informação relativa a esta performance resulta sobretudo da apresentação de Anastasia Merkouri no Curso de Verão de 2008 em Epidauro, a quem agradeço todas as sugestões dadas. 
de trabalhadoras com profissões - e idades - variadas, dançava por norma com um movimento não sincronizado, ao som de música sobretudo africana, baseada em ritmos de percussões. Roupas modernas, de distintos estilos, vestiam os diversos actores. Na sua produção, Langhoff fez Dioniso entrar em cena nu, com uma máscara de touro; ao perceber a sua nudez, o deus vestiu-se em palco, utilizando as roupas penduradas na corda, numa atitude sugestiva da metamorfose de um animal num homem. Penteu, por sua vez, disfarçado de mulher, apareceu montado num cavalo, fazendo lembrar uma noiva que se dirige para a cerimónia do seu casamento. Num gesto expressivo de um costume grego contemporâneo após um funeral, um membro do coro ofereceu uma chávena de café a Cadmo no final da peça, depois de Agave ter compreendido que afinal havia assassinado o seu próprio filho.

Os inúmeros elementos da actualidade que o encenador combinou com os da tradição antiga suscitaram fortes reacções, evidenciando um relacionamento de fractura entre o 'ego' e o 'alter'. O drama ático da Antiguidade constitui-se para os Helenos como instrumento de filiação identitária, i. e., como um património comum, com valores que os distinguem da perspectiva adoptada por Langhoff, da qual se distanciam. A audiência sentiu-se chocada com o tratamento concedido à peça clássica e, embora uma boa parte tenha aplaudido a performance, espectadores houve que apuparam os actores durante a representação, e outros que saíram a meio, manifestando desse modo a sua insatisfação e desaprovação perante as transgressões visíveis num espectáculo que esperavam - e desejavam - mais convencional. Tão pouco a recepção dos críticos foi favorável, sendo que muitos deles, desagradados, nem sequer manifestaram uma opinião documentada sobre a produção. Os antecedentes culturais do povo helénico dificilmente o instigariam a reconhecer-se nas directivas de Langhoff.

Ambas as produções mencionadas na presente reflexão evidenciam que algumas performances do teatro antigo na Grécia contemporânea são sentidas como transgressoras da tradição, embora por motivos distintos. Na verdade, a recepção de As Aves levadas à cena por Karolus Koun, há umas boas décadas atrás, i. e., no final dos anos cinquenta do século passado, ocorreu 
numa altura em que a audiência grega não estava acostumada a inovações na forma de representar o drama clássico, ainda que as alterações se prendessem com elementos coreográficos, por exemplo; respeitar a peça de outrora e a mensagem respectiva implicava uma encenação estritamente convencional. No caso das Bacantes dirigidas por Langhoff, porém, trata-se de um espectáculo com uma natureza provocatória à partida, em termos éticos, estéticos, religiosos, no intuito de impor uma ousada perspectiva pessoal a um público com uma forte identidade colectiva no que concerne ao orgulho de ser o herdeiro directo do teatro clássico ${ }^{13}$. Ao procurar modernizar as Bacantes, na mira de as aproximar da realidade contemporânea, Langhoff sacrificou o texto, tentando criar novas identidades no público de hoje. Todavia, esta produção, ao confrontar os espectadores gregos com controversos elementos inovadores, exigia-lhes uma renegociação com o passado, que não se mostraram disponíveis para aceitar: boa parte da audiência não se identificou com as propostas do director.

\section{Bibliografia}

E. Fischer-Lichte (2008), "Transformations of Ancient Greek Theatre", in Exploring European Identities/Ideologies by means of (Re)Presentations of Ancient Greek Drama: Intensive Course. Epidavros, 27-32.

E. Hall, S. Harrop, eds. (2010) Theorising performance: Greek drama, cultural history and critical pratice. London.

H. Schoenmakers, P. Mavromoustakos (2010), "Changing attitudes towards ancient drama in theatre practice", in M.F.S. Silva, S. H. Marques, eds., Tragic Heroins on Ancient and Modern Stage. Coimbra.

K. Koun (1987), "Open versus closed stage", in Doing theatre for soul. Athens, cit. in P. Mavromoustakos 2008, Exploring European Identities/Ideologies by means of (Re)Presentations of Ancient Greek Drama: Intensive Course. Epidavros 196-197.

V. López Recio (2009), "El Director Vanguardista Károlos Kun en su Aventura Escénica con el Drama Antiguo", in A. López, A. Pociña (Eds.), En Recuerdo de Beatriz Rabaza. Comedias, Tragedias y Leyendas Grecorromanas en el Teatro del Siglo XX. Granada, 367-379.

13 Mais recentemente ainda, a Medeia de Eurípides, levada à cena em Agosto de 2008 em Epidauro, sob a direcção do russo A. Vasiliev, causou um forte impacto negativo na audiência. De facto, como nas Bacantes encenadas por Langhoff, também onze anos depois houve espectadores a abandonar o teatro e a assobiar os actores. 
P. Mavromoustakos (2008), "Ancient Greek Drama on the Modern Greek Stage: the question of theatrical space", Exploring European Identities/Ideologies by means of (Re)Presentations of Ancient Greek Drama: Intensive Course. Epidavros, 183-197.

E. Stehlíková (2008), "The History of Performances in Europe", in Exploring European Identities/ Ideologies by means of (Re)Presentations of Ancient Greek Drama: Intensive Course. Epidavros, $175-181$.

D. Wiles (2000), Greek Theatre Performance: an Introduction. Cambridge. 